\title{
OPTIMIZATION OF PRESTRESSED CONCRETE BRIDGE DECKS
}

\author{
A. Samartín Quiroga and M. A. Utrilla Arroyo
}

\begin{abstract}
In this paper a summary of the methods presently used for optimization of prestressed concrete bridge decks is given. By means of linear optimization the sizes of the prestressing cables with a given fixed geometry are obtained. This simple procedure of linear optimization is also used to obtain the 'best' cable profile, by combining a series of feasible cable profiles. The results are compared with the ones obtained by other researchers. A step ahead in the field of optimization of prestressed bridge decks is the simultaneous search of the geometry and size of the prestressing cables. A non-linear programming for optimization is used, namely, 'the steepest gradient method'. The results obtained are compared with the ones computed previously by means of linear programming techniques. Finally, the general problem of structural optimization is considered. This problem consists in finding the sizes and geometries of the prestressing cables as well as the longitudinal variation of the concrete section.
\end{abstract}

\section{INTRODUCTION}

Prestressed concrete bridges are frequently used in motorway design when intersecting traffic occurs. Durability, ease of construction and maintenance, aesthetics etc., are some advantages of their use. In the design of a prestressed concrete bridge deck the analysis and the arrangement of the prestressed cables represent a very important task. Usually this task is carried out by using heuristic rules or previous engineering experience, and the validity of the prestressed design is in this way checked. It may be very interesting in this respect to have available an automatic procedure to design the force and geometry of the prestressing cables, with a minimum of designer's intervention.

Many researchers [1-4] have been working in this direction, i.e. to find the optimum prestress design for a bridge deck. In order to handle the problem efficiently, most of them introduce drastic simplifications. Linearization, specialization to a class of structures (simply supported or continuous beams, portal frames, etc.), availability of an initial feasible solution, etc. are some examples of these simplifications. However, the development of this research work has been usually confined to the academic standpoints without being extended to practical applications.

In this paper, a progress report on the authors' research of automatic design of prestressed concrete bridges is presented. This research is carried out inside of a larger research project related to the development of an expert system on bridge design. In the following section the main steps of the design of a prestressed concrete bridge will be first reported. In the subsequent sections other optimization problems will be described and some examples will be given.

\section{DESIGN OF PRESTRESSED CONCRETE BRIDGE DECKS: STEPS}

The main steps in the design of prestressed concrete bridge decks are summarized as follows:

1. Loading and structural definition. The magnitudes of the loads are given in the applicable codes and recommendations. The different loading combinations in service and ultimate states are also given in the normative. The concrete, reinforced and prestressed steel properties and sizes are also defined by the local conditions. Finally the type of structure (simply supported or continuous beam, portal frame, etc.) is given at this level. The span lengths and construction techniques (precast, cast in place, cantilever, pushing, etc.) are assumed to be known.

2. Analysis of the deck: stress-resultants. The stressresults are computed for the different construction stages and loadings by using an appropriate structural model. Here, it will be assumed, the bridge deck is a beamlike structure, i.e. a chain of 1-D (beam) elements can model the deck in order to obtain the mean displacements and the total stress-resultants acting in the whole cross-section. The transversal distributions of the displacements and stressresultants in a section can be analysed according to the type of cross-section (slab, multigirder, box, etc.) by the use of different methods (orthotropic plate, folded plate structure, etc.). Details can be found in the specialized literature [5].

3. Prestress definition and analysis. The design of the prestress cables is carried out in two steps: definition of the geometry of each cable family (group of cables that can be treated in the analysis as a single unit) and the computation of prestress forces (i.e. the sizes of each cable family). Usually this step of the analysis is carried out by trial and error procedures. Some initial prestress geometry and prestressing forces are assumed, and they are checked in the two states-service and ultimate states-according to the two following steps.

4. Service state. The displacements and the stresses at each design section of the bridge deck are computed in this state. The obtained results are to be limited according to the normative.

5. Ultimate state. The displacements and the stresses at each design section of the bridge are computed for the ultimate state. The safety coefficients obtained with these values should be greater than the specified ones.

6. Passive reinforcement. From the service and ultimate state analysis the amount of longitudinal passive reinforcement can be determinated. Also the amount of transversal passive and/or the prestressed reinforcement can be computed from the longitudinal and transversal stresses (shear, torsional, longitudinal stresses) at the two states.

From the above discussion the importance of the step 3 can be ascertained. Usually, the service longitudinal stresses 


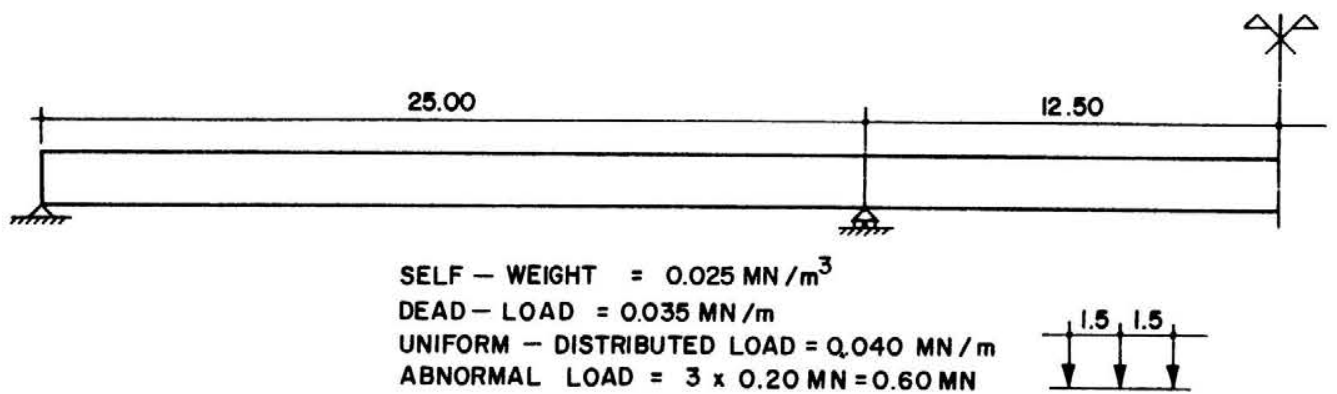

Fig. 1. Example 1: longitudinal section.

(those due to the bending moment and axial forces) are used to check the feasibility of the prestress design. However, if these longitudinal stresses are allowable, no new design for prestress cables is considered. That means, in this way an optimal prestressed is not normally obtained.

\section{OPTIMAL PRESTRESS FORCE}

In order to find the optimal design of the prestress in a bridge, a first problem to be solved is presented. It is assumed that the geometry of the prestress families is known and the forces, $T_{i}$, of each family have to be found, in order that the longitudinal service stress along the bridge deck be allowable. The following values are known at this step:

The longitudinal stresses $\sigma_{l}^{j}=\left(\sigma s_{l}^{j} ; \sigma i_{l}^{j}\right)$ at each section $j$, due to loading combination $l$. Two fibres are considered at each section namely, top and bottom fibres, and the corresponding stresses are $\sigma s_{l}^{j}$ and $\sigma i_{l}^{j}$, respectively.
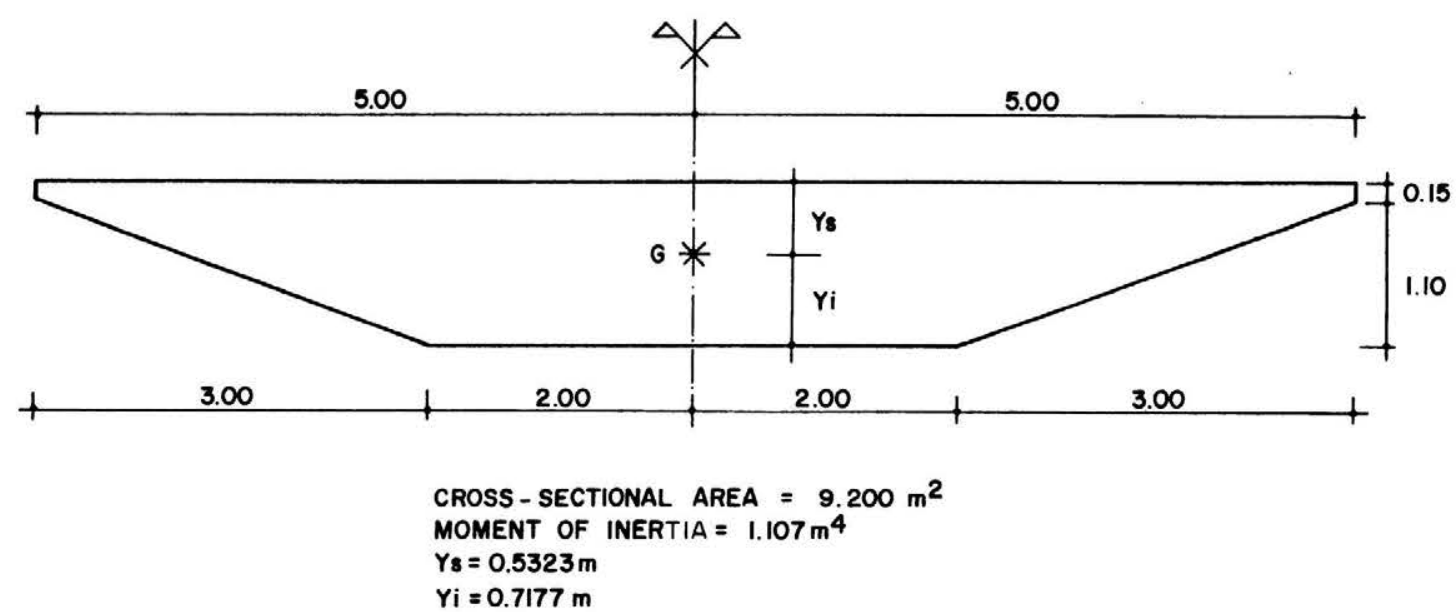

Fig. 2. Example 1: cross-section.

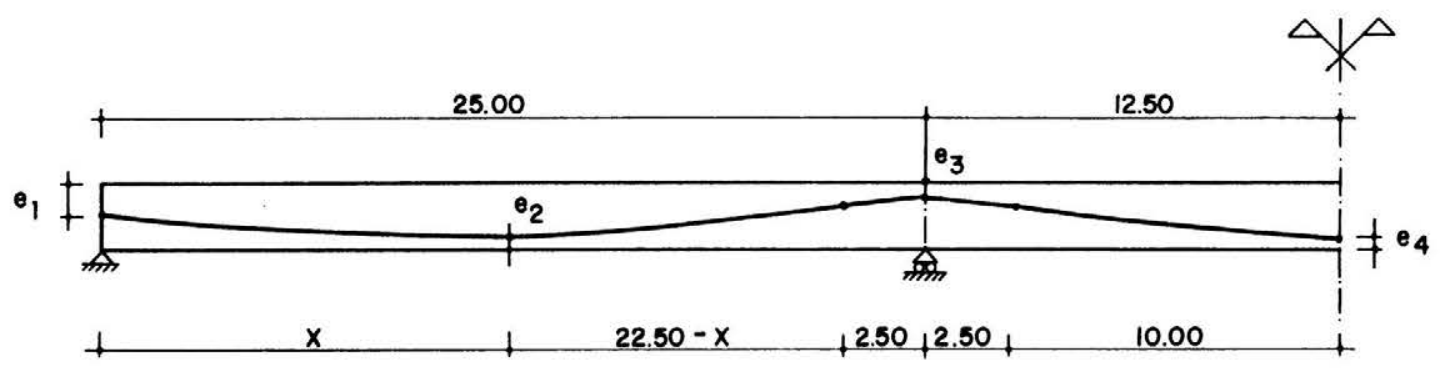

ei $\min =0.15 \mathrm{~m}$

\begin{tabular}{|c|c|c|c|c|c|}
\hline FAMILY & $\underline{x(m)}$ & $\theta_{1}(\mathrm{~m})$ & ${ }^{\theta} 2(\mathrm{~m})$ & $\theta_{3}(\mathrm{~m})$ & $84(\mathrm{~m})$ \\
\hline 1 & 12.50 & 0.5323 & 0.15 & 0.15 & 0.15 \\
\hline 2 & 12.50 & 0.7583 & 0.15 & 0.15 & 0.15 \\
\hline 3 & 10.00 & 0.7583 & 0.15 & 0.15 & 0.15 \\
\hline
\end{tabular}

Fig. 3. Example 1: prestress cable profiles. 
The geometry of the prestress family $i$, defined by the ordinates $y_{i}=y_{i}(s)$ as function of the longitudinal distance $s$.

The longitudinal stresses $\bar{\sigma}_{l, k}^{j}=\left(\bar{\sigma} s_{l, k}^{i} ; \bar{\sigma} i_{l, k}^{i}\right)$ at each section $j$ due to the prestress family $i$ with an unit force, i.e. $T_{i}=1$ at prestress state $k(k=0$ initial prestress, $k=1$ final prestress).

The allowable values $\sigma_{l}^{\prime} ; \sigma_{l}$ of the longitudinal stresses, compression (+) and tension (-), respectively, for the loading combination.

The unknown prestressing forces $T_{i}$ are found by using the following minimizing condition

$$
\min O F=\sum_{i=1}^{l} L_{i} T_{i}
$$
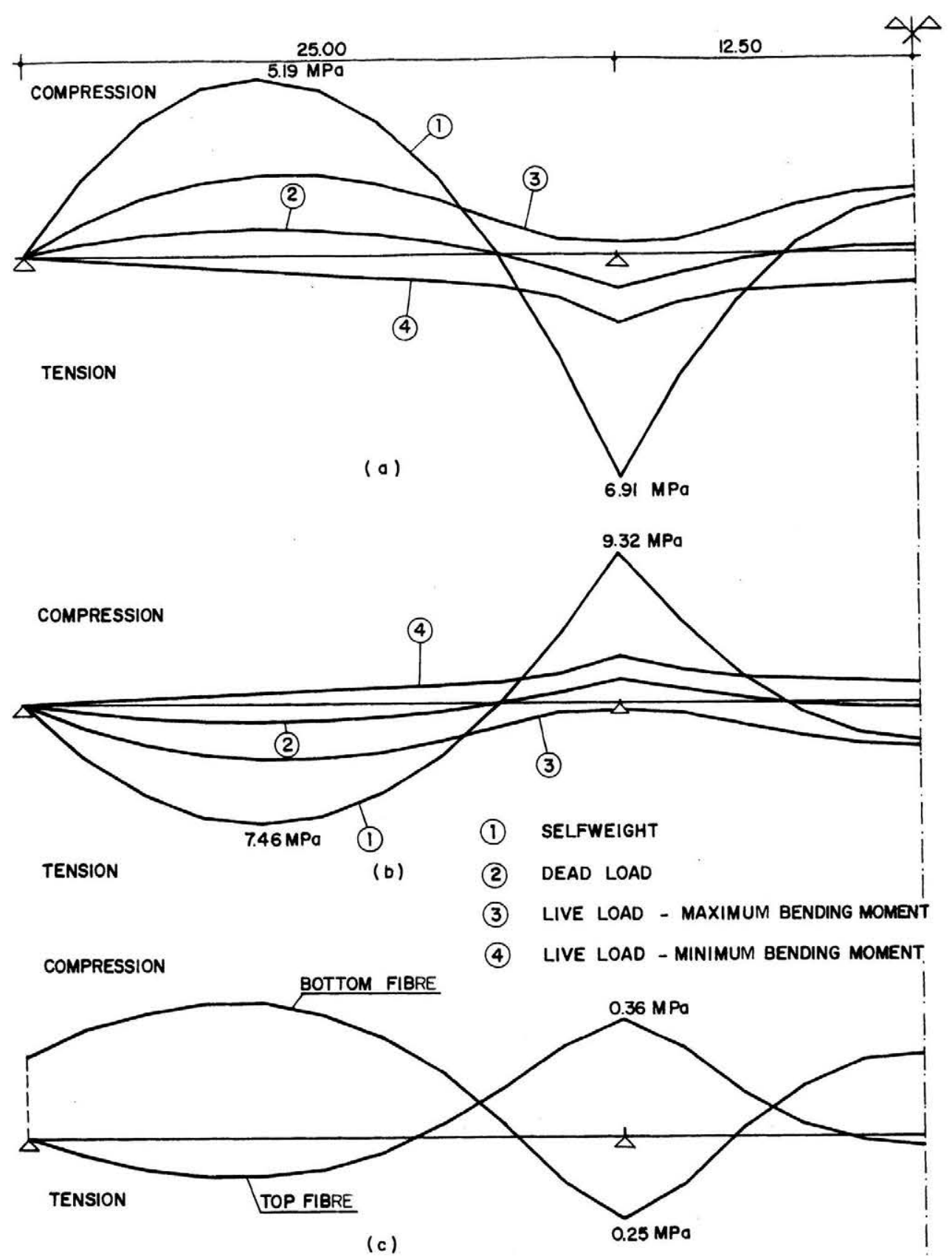

(c)

Fig. 4. Example 1: stress variation along the deck for different loading conditions: (a) top fibre, (b) bottom fibre, (c) prestress unit cable (family 3). 
Table 1. Example 1: results

\begin{tabular}{cc}
\hline Family & Force $T^{i}(\mathrm{MN})$ \\
\hline 1 & 0.00 \\
2 & 11.14 \\
3 & 18.46 \\
\hline
\end{tabular}

when $I$ is the number of family of cables, $L$ is the number of loading combinations, $J$ is the number of sections to be checked, $L_{i}$ is the length of cable $i$.

The value of $k(0,1)$ depends on the loading combinations under consideration. The following three loading combinations have been considered: $l=1$; construction. Selfweight + initial prestress. $l=2$; service 1 . Selfweight + final prestress + dead load + live loading at positions to produce maximum bending moment at section $j . l=3$; service 2 . Selfweight + final prestress + dead load + live loading at positions to produce minimum bending moment at section $j$.

The problem represented by eqns (1) and (2), can be solved by linear programming. Several methods can be applied [7]. Here the Simplex method has been used. In some cases no solution exists, which means that the geometry of the prestress is inappropriate, and it should be changed. Also, if from a particular family of prestress results a null value for its force is obtained, it means that, the family should not be considered in the design.

\section{Example 1}

In order to illustrate the capabilities of the procedure just described, the following example will be considered: the bridge deck, a three-span continuous beam, is shown in Fig. 1. The transversal cross-section is represented in Fig. 2 and it corresponds to a slab deck. In Fig. 3, the prestress cable profiles are given for the different families. Finally in Fig. 4 the top and bottom stress variation along the deck are also shown for the different loading conditions include the prestress unit cables.

The application of the linear programming (Simplex method) produces the results summarized in Table 1 .

\section{OPTIMAL PRESTRESS DESIGN: GEOMETRY AND FORCES}

The actual problem of automatic design of prestressed bridge deck has unknowns the geometry of the different families of cables and the prestress forces $T_{i}$ as well.

In order to reduce the size of the problem, the geometry of the cables can be defined at specified locations $\left(s=s_{1}^{i}, s=s_{2}^{i}, \ldots, s=s_{N}^{i}\right)$ or each family $i$ by the ordinate and the slope of the profile of the cable. Then, the unknowns are for each family $i$, the force $T^{i}$ and set of values $y_{n}^{i}, \theta_{n}^{i}$ corresponding to the ordinate and the slope of the cable profile at the section $s=s_{n}^{i}$ $(i=1,2, \ldots, I ; n=1,2, \ldots, N)$.

In order to solve the problem of finding the prestress design defined by the unknowns $T_{i}, y_{n}^{i}, \theta_{n}^{i}(i=1,2, \ldots, I)$ the objective function $O F$ given by eqn (1) is minimized. The following step by step procedure will be applied: let it be a current prestress configuration, $y_{n}^{i(m)}, \theta_{n}^{i(m)}$ corresponding to the $m$ th computational step. For this known configuration, the optimal prestress forces can be obtained by linear programming as it was described previously in Section 3, and the value of the objective function $O F^{(m)}$ can be computed accordingly, i.e. the value

$$
O F^{m}=\sum_{i=1}^{l} L_{i} T_{i}^{(m)} .
$$

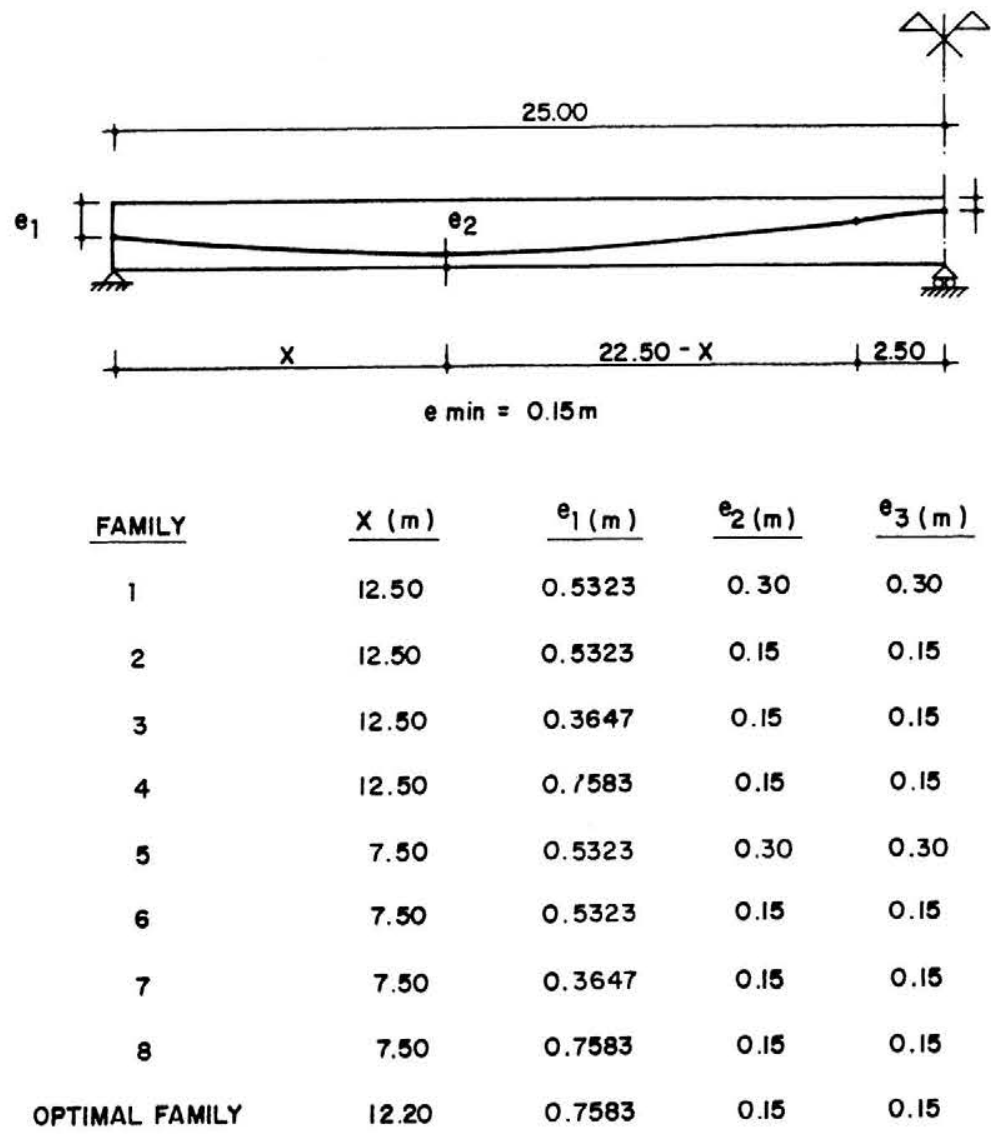

Fig. 5. Example 2: prestress cable profiles, two span beam. 


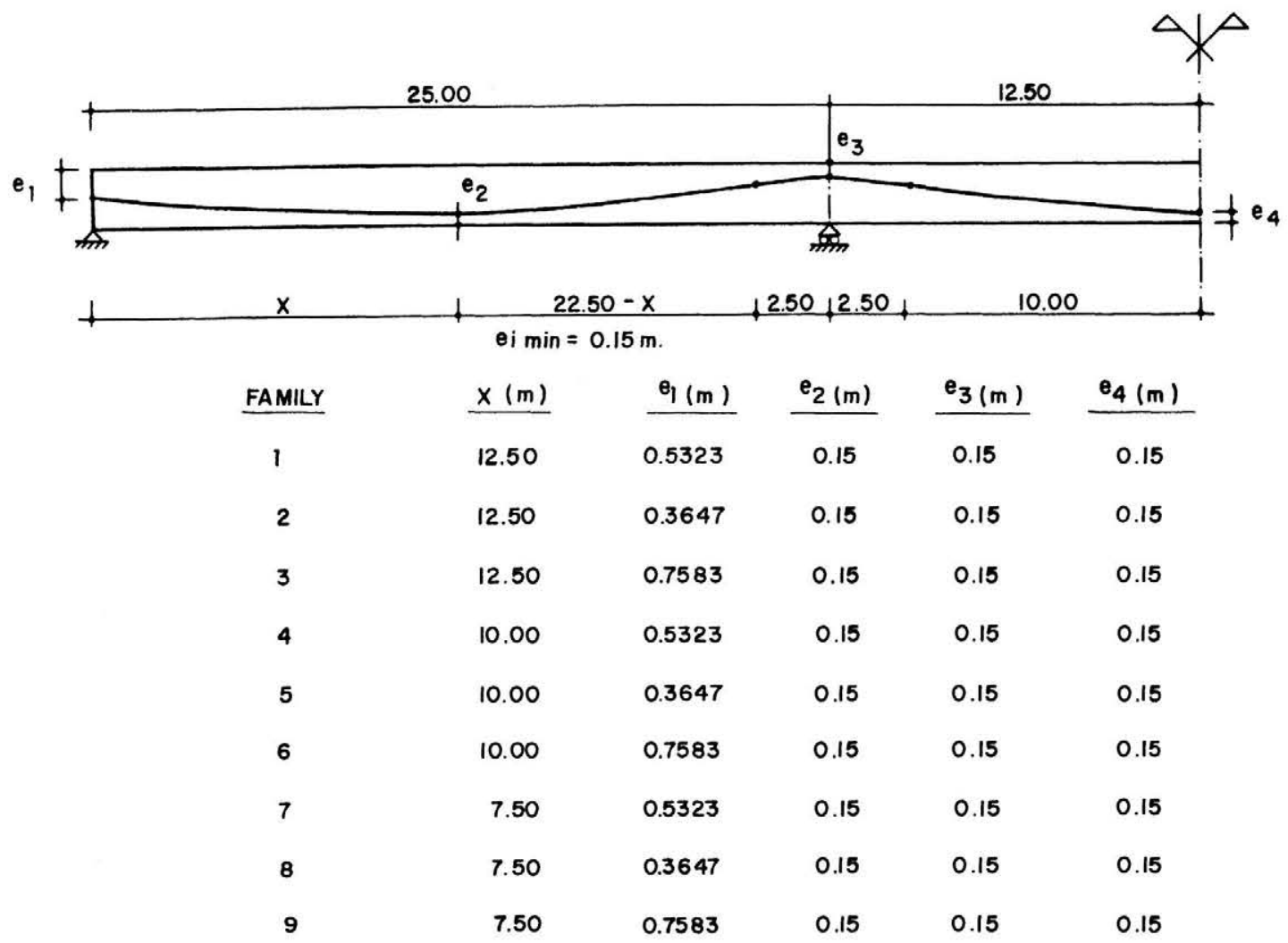

Fig. 6. Example 2: prestress cable profiles, three span beam.

At this $m$ th configuration the partial derivatives of the objective function $O F$ with respect to variables $y_{n}^{i}, \theta_{n}^{i}$ can be computed as follows:

$$
\begin{aligned}
& \left.\frac{\partial O F}{\partial y_{n}^{i}}\right|_{m} \bumpeq \frac{\Delta O F^{(m)}}{\Delta y_{n}^{i(m)}} \\
& \left.\frac{\partial O F}{\partial \theta_{n}^{i}}\right|_{m} \bumpeq \frac{\Delta O F^{(m)}}{\Delta \theta_{n}^{i(m)}}
\end{aligned}
$$

or using a common notation

$$
\left.\frac{\partial O F}{\partial r_{n}^{i}}\right|_{m} \bumpeq \frac{\Delta O F^{(m)}}{\Delta r_{n}^{k(m)}},
$$

where

$$
r_{n}^{i}=y_{n}^{i} \text { or } \theta_{n}^{i} \text {. }
$$

To compute $\Delta O F^{(m)}$, the configuration $(m)$ is modified by changing the value to the new one $r_{n}^{(k)}+\Delta r$, where $\Delta r=\Delta y$ or $\Delta \theta$ has a given fixed incremental value for the variable $y_{n}^{i}$ or $\theta_{n}^{i}$ normally the admissible error for the definition of the cable geometry.

For this modified configuration the linear programming problem of Section 3 is solved and therefore the derivative $\partial O F / \partial r_{n}^{i} I_{m}$ is computed using (6).

This procedure is applied to each variable $(i=$ $1,2, \ldots, I, n=1,2, \ldots, N)$ and the gradient of the $O F$ at configuration $m$ is obtained, i.e. the vector $\nabla O F^{(m)}$ defined as follows:

$$
\nabla O F^{(m)}=\left\{\nabla_{y} O F^{(m)}, \nabla_{\theta} O F^{(m)}\right\}^{T}
$$

where

$$
\begin{aligned}
& \nabla_{y} O F^{(m)}=\left\{\frac{\Delta O F^{(m)}}{\Delta y_{1}^{I(m)}}, \frac{\Delta O F^{(m)}}{\Delta y_{2}^{I(m)}}, \ldots, \frac{\Delta O F^{(m)}}{\Delta y_{n}^{I(m)}}\right\} \\
& \nabla_{\theta} O F^{(m)}=\left\{\frac{\Delta O F^{(m)}}{\Delta \theta_{1}^{!(m)}}, \frac{\Delta O F^{(m)}}{\Delta \theta_{2}^{!(m)}}, \ldots, \frac{\Delta O F^{(m)}}{\Delta \theta_{n}^{I(m)}}\right\} .
\end{aligned}
$$

Table 2. Example 2: results for two span beam and three span beam

\begin{tabular}{cc}
\hline Family & Force $T^{i}(\mathrm{MN})$ \\
\hline Two span beam & \\
1 & 0.00 \\
2 & 0.00 \\
3 & 0.00 \\
4 & 27.21 \\
5 & 0.00 \\
6 & 0.00 \\
7 & 0.00 \\
8 & 1.62 \\
Optimal force & 28.83 \\
& \\
Three span beam & \\
1 & 0.00 \\
2 & 0.00 \\
3 & 11.14 \\
4 & 0.00 \\
5 & 0.00 \\
6 & 18.46 \\
7 & 0.00 \\
8 & 0.00 \\
9 & 0.00 \\
Optimal force & 29.60 \\
\hline
\end{tabular}




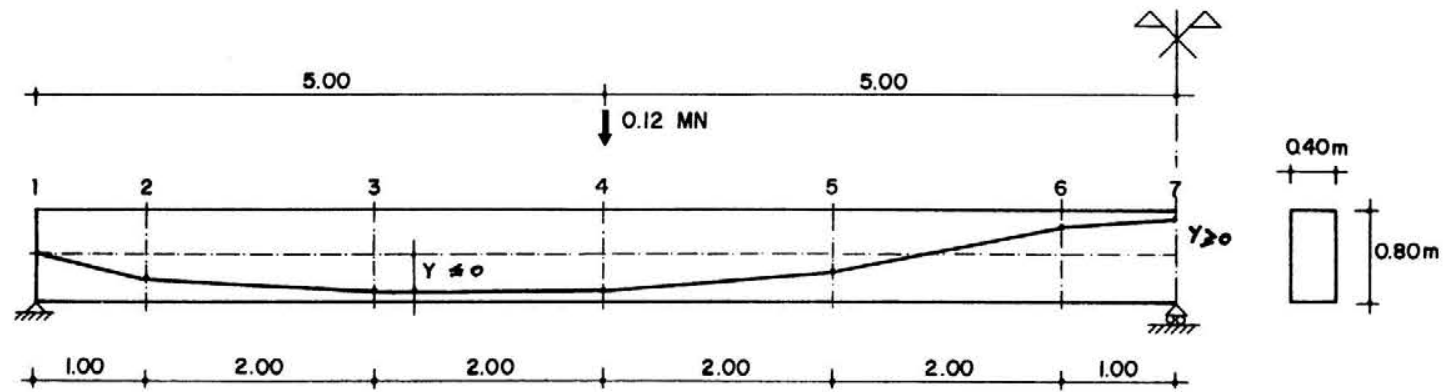

LONGITUDINAL SECTION

CROSS SECTION

DESIGN VARIABLE $Y i \quad 0.30 \geqslant Y i \neq-0.30 \quad i=1,2, \ldots \ldots, 13$

Fig. 7. Example 3.

The new position for the next computational step is

$$
r^{(m+1)}=r(m)+\lambda_{y} \nabla_{y} O F^{(m)}+\lambda_{\theta} \nabla_{\theta} O F^{(m)},
$$

where $\lambda_{y}>0$ is obtained from the condition

$$
\lambda_{y} \leqslant \frac{\Delta y}{\max _{i, n}\left|\frac{\Delta O F^{(m)}}{\Delta y_{n}^{(m)}}\right|}
$$

and $\lambda_{\theta}>0$ is also found from

$$
\lambda_{\theta} \leqslant \frac{\Delta \theta}{\max _{i, n}\left|\frac{\Delta O F^{(m)} \mid}{\Delta \theta_{n}^{(m)}}\right|} .
$$

This step by step procedure stops when $\Delta O F^{(m)}$ is less than an admissible error for all the $\Delta r_{n}^{(m)}$. The initial (starting) geometry is obtained from a feasible solution. A simplified approach of finding a feasible solution in a near optimal prestress design can be applied in many cases the following one: every family $i$ to be determinated is considered to be a linear combination of given subfamilies, i.e. at every section $j$

$$
y_{i}(s)=\lambda_{\text {ih }} y_{i h}(s), \quad i=1,2, \ldots, I, h=1,2, \ldots, H .
$$

The unknown coefficients $\lambda_{i h}$ are obtained from the solution of the linear programming corresponding to the whole set of families of cables, i.e. with the following objective function

$$
O F=\sum_{i=1}^{I} \sum_{h=1}^{H} T_{i h} L_{i} .
$$

Table 3. Example 3: results

\begin{tabular}{cc}
\hline Section & $Y^{i}(\mathrm{~m})$ \\
\hline 1 & 0.00 \\
2 & -0.20 \\
3 & -0.30 \\
4 & -0.30 \\
5 & -0.15 \\
6 & 0.25 \\
7 & 0.30 \\
Optimal force & $0.308 \mathrm{MN}$ \\
\hline
\end{tabular}

The unknown geometry of the family $i$ is, then

$$
y_{i}(s)=\frac{T_{i h}}{\sum_{h=1}^{H} T_{i h}} y_{i h}(s), \quad \text { i.e. } \lambda_{i h}=\frac{T_{i h}}{\sum_{h=1}^{H} T_{i h}} .
$$

\section{Example 2}

In order to assess the efficiency of the approximative procedure described in the previous section two cases will be analysed. The first corresponds to a two span beam and the second to a three span beam with equal span lengths (Figs 5 and 6). In both cases the transversal cross-section and the external loadings are identical to the ones given in Example 1.

Assuming several different families of prestress cables, the optimal solution is obtained by the composition rule given by (10). In some instances, the optimal profile was a single cable, corresponding to the only one force with non-zero values. Table 2 shows the results obtained from this approach.

\section{Example 3}

As a final illustrative example of the capabilities of this approximative optimization technique a simple case studied in ref. [7] will be considered. The two span continuous beam of Fig. 7 has been specifically studied. Some simplifications in the cable profile (composed by straight segments between loads) and computation of the prestress losses (by linearizing all these losses) have been considered and the optimal cable profile for the load represented in Fig. 7 has been obtained in this reference. The results of this ref. [7] (Table 3) are compared to the ones, given in Table 4, that have obtained from the approximative procedure already described with three tentative basic cable profiles (Fig. 8). It can be observed a very close results in both methods.

\section{FURTHER DEVELOPMENTS}

There are several papers related to the optimization of bridge structures. Some of them are treating the prestress

Table 4. Example 3: results

\begin{tabular}{cc}
\hline Family & Force $T^{i}(\mathrm{MN})$ \\
\hline 1 & 0.000 \\
2 & 0.307 \\
3 & 0.000 \\
Optimal force & 0.307 \\
\hline
\end{tabular}




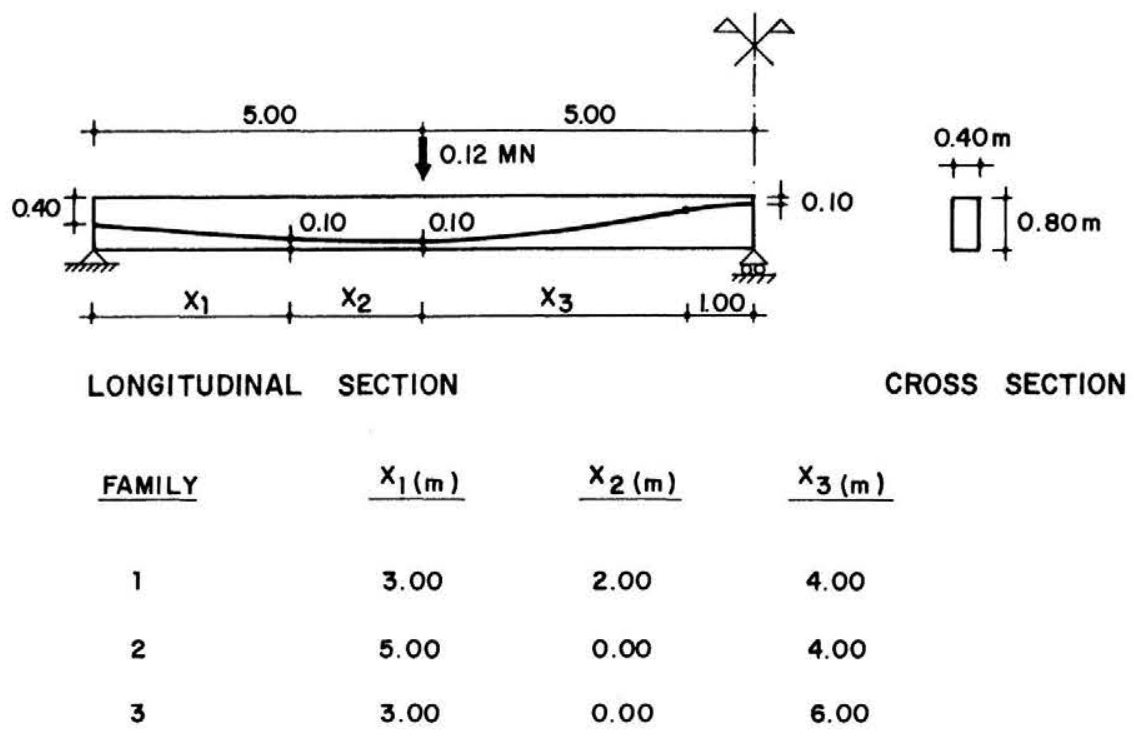

Fig. 8. Example 3.

size and geometry, sections properties, variation of these sections along the bridge etc. References [3] and [4] are representative of the efforts in this direction using general methods of optimization. The excellent paper of Templeman and Winterbottom [8] is an example of a complete work on a specific optimization problem, namely on the design of concrete cellular bridge decks. The main difficulty of this type of analysis lies in the numerical troubles caused by non-convexity and strong non-linearity properties of the optimization programming needed to solve this general type of problems

\section{CONCLUSIONS}

An automatic design of prestressed concrete bridge decks has been presented. Although in the present form the model is simplified only to the study of service longitudinal bending stresses, it already represents a useful tool deserving to be included inside of an expert system for bridges. Moreover, extensions to include ultimate analysis, shear and torsional stresses and transversal bending stresses are foreseen. Some realistic examples have been treated with a minimum of computational effort.

\section{REFERENCES}

1. R. Maquoi and J. Randal, Approache realiste du dimensionnement optimal des ponts precoinstraints hyperstatiques. Ann. Trav. Pub. Belgium (1977).

2. R. Maquoi and J. Randal, Optimal layout of cables in prestressed indeterminate bridges. Revue Roumaine de Sciences Techniques.

3. V. Kirsch, Optimized prestressing by linear programming. Int. J. Numer. Meth. Engng 7 (1973).

4. V. Kirsch, Optimum design of prestressed beams. Comput. Struct. (1972).

5. A. González, Metodo para el dimensionamiento directo del pretensado en puentes hiperstaticos. Tesis doctoral. ETSICCP, University P, Madrid (1989).

6. A. Samartín, Cálculo de Estructuras de Puentes de Hormigón. Ed. Rueda, Madrid (1982).

7. S. Hernández Ibañez, Metodos de diseño óptimo de estructuras. Colegio de ICCP, Madrid (1990).

8. A. B. Templeman and S. K. Winterbottom, Optimum design of concrete cellular spine beam bridge decks. Proc. Instn. Civ. Engrs. Part 2, 67 (1979). 